\title{
Los conventillos de Valparaíso, 1880-1920: Percepción de barrios y viviendas marginales
}

María Ximena Urbina C.

\section{Filiación}

La autora es Licenciada en Historia por la Universidad Católica de Valparaíso, y candidata a Magíster en Historia por la misma universidad. Este tema fue presentado en las VIII Jornadas de Preservación Arquitectónica y Urbana, realizadas en la Universidad de La Serena en noviembre del 2001. Es también parte de nuestra investigación para optar al grado de Magíster.

\section{Resumen}

Las viviendas populares, los conventillos y ranchos urbanos y semiurbanos, reflejaron el modo de ser de una cultura, el modo de vivir de la gran mayoría de los porteños en tiempos en que la ciudad creció demográficamente y las viviendas y áreas llamadas "decentes" no daban abasto a la imperiosidad de buscar ganarse la vida en la urbe y hacerse citadino. En los barrios marginales de ranchos y de conventillos se expresaba lo más genuino de la vida urbana, lo popular, la vida de los más humildes que forjaron una forma de existencia arrabalera, quizá un substrato importante de la chilenidad. En este artículo nuestro objetivo es distinguir una tipología de conventillos - sin entrar en detalles de su descripción -, y perfilar la imagen, representación mental o percepción que de ellos se tenía en su época dorada, 1880-1920.

\section{Palabras claves}

Conventillos, Valparaíso, percepción, vivienda, cité.

\begin{abstract}
Popular housing, "conventillos", urban and semi-urban ranches show the way of life and culture most of the people in Valparaiso in a time when the city experimented a population growth and proper housing was not enough to cover the growing demand due to the greater need to make a living in the city and becoming a city dweller. In this low class neighborhoods, ranches and "conventillos" the most genuine aspects of city life, that which is popular, the life of the humble, the slum dwellers, which is perhaps an important constituent of what is Chilean. In this article our objective is to define a type of "conventillos", nevertheless not describing them in detail, and then establish and image, a mental representation or perception that people had of them during their 'golden age' between the years 1880 and 1920.
\end{abstract}

\section{Key words}

Conventillos, Valparaíso, perception, housing, cité. 


\section{Sumario}

1.-Los conventillos de Valparaíso

2.- Tipologías

3. Importancia del estudio de los conventillos: su valor histórico

4.- Conventillo y Cité

5. Percepción o imaginario de los barrios pobres

6. Imagen popular del conventillo

7. Percepción periodística y oficial del conventillo

8.-En suma

Referencias

\section{1.- Los conventillos de Valparaíso}

La vivienda, como necesidad humana instintiva y prioritaria, es fundamental para la supervivencia del ser humano, por miserable que ésta sea, y es la primera fuente en que el hombre llega a la vida, se nutre y se desarrolla. Es su condición de ser espacio de "instalación efectiva del hombre" lo que la hace vivienda (1), porque es, además, un espacio de convivencia, crea redes familiares y sociales y no es sólo el lugar de residencia. Dice Alfredo Moffatt que la casa "se incorpora al esquema corporal y completa la organización de vida, es el entorno, lo que los alemanes llaman 'umwelt' y los ingleses 'enviroment', o sea, el mundo que los rodea" (2). No importa cuán humilde sea, la vivienda "hace al hombre", lo acoge y a veces condiciona su actuar. Su tamaño, iluminación, ventilación, materiales, decoración, en fin, menaje, inciden en el modo de vida.

La mayoría de la población pobre de las más importantes ciudades de la época de la Cuestión Social, habitaba conventillos, y sus formas de actuar responden al habitar colectivamente en espacios compartidos, pequeños y sucios. La pobreza y la atracción que ejercían las ciudades, más la especulación comercial de los propietarios, generalizaron este tipo de vivienda (3). Los conventillos nacieron y se multiplicaron como respuesta a la demanda habitacional de los sectores populares, a la falta de terrenos para levantar sus viviendas y al progresivo mayor valor del suelo. En su origen comparecen la migración campo-ciudad y los intereses de un sector de la sociedad que aprovechó la oportunidad para especular con las rentas por cuartos (4).

En el Reglamento de Conventillos de 1899, fue definido como "la propiedad destinada a arrendamiento por piezas o por secciones, a la gente proletaria" en que "varias piezas o cuerpos de edificios arrendados a distintas personas tengan patio o zaguán en común" (5). Sin embargo, el conventillo de Valparaíso no fue diseñado como tal, ni se puso en práctica el concepto de habitación colectiva de un piso y patio central, o conjunto de departamentos en una construcción en forma de "U" con pasillo central abierto a la calle. El edificio que más se aproxima a esa idea es el que adquirió Juana Ross en el cerro Cordillera en 1898. Era una construcción de tres pisos en una superficie de media cuadra, y fue transformado en conventillo formal para los obreros 


\section{REVISTA DE \\ URBAANISMO}

http://revistaurbanismo.uchile.cl

de la "Unión Social de Orden y Trabajo", acondicionándolo para tal fin y dotándolo de baños interiores. Fue inaugurado oficialmente en 1898 (6).

Los conventillos de Valparaíso surgieron y proliferaron de un modo distinto a los de Santiago y otras ciudades chilenas, porque el emplazamiento urbano y la topografía de los cerros terminaron por singularizar las respuestas a las necesidades urbanas del Puerto. Si podemos percibir que los conventillos de Valparaíso tienen algunos rasgos físicos propios, su origen, existencia y la sociabilidad particular que se dio en ellos justifican un estudio que permita reconocer similitudes y distinguir peculiaridades en relación con los mismos de Santiago.

Plan y cerro eran indistintamente zonas de conventillos. Mientras en el plan por una parte, predominaban los conventillos en las casas con zaguán, patio central y habitaciones, -otrora habitadas por familias que se mudaron a lugares de mejor tono-, la subdivisión permitía el hacinamiento y la rentabilidad para el propietario, al modo que se usaba en Santiago. En cambio, en los cerros predominaban los conventillos a modo de ranchos colectivos construidos improvisadamente con materiales de desecho, compartiendo sitios con ranchos propiamente tales e individuales que, no obstante, en lenguaje común se llamaban, también, conventillos. Eran construidos indistintamente con materiales muy heterogéneos, los más disponibles y los que costara menos trabajo acarrear cerro arriba. Algunos eran de barro, aunque el material utilizado por la mayoría de las del plan era "caña y barro" (7), sin perjuicio de toda clase de tablas, o desechos de naufragios, maderas podridas, telas o harapos, cueros de animales, latas o cartones. Joaquín Edwards Bello agrega "rieles, adoquines, totora" (8), "desperdicios de la ciudad".

Generalmente un zaguán les servía de entrada. Traspuesto el zaguán se apreciaba una edificación compuesta de "pasadizos húmedos y estrechos [que] desembocaban en otros pasadizos, y a cada vuelta bruscos chiñones de aire nos daban la sensación de ir a lo largo de las cañerías de una mina", decía un visitante que recorrió su interior en 1907. Edwards agrega que, "tras muchos vericuetos, nos hallamos por fin en un espacio común, al pie del cerro, en donde iban a dar los diversos pasadizos" (9). Al ingresar al patio de la edificación se veían las habitaciones. La disposición de los cuartos era hacia un lado, o hacia ambas alas de "una estrecha vía que corría entre largas filas de piezas ordenadas a la manera de cabinas o camarotes de los vapores" (10), dice un francés que visitó Valparaíso en los años ochenta. Esta analogía con los vapores permite formarnos una idea de la estrechez y uniformidad del espacio habitable (11). Otros mostraban diferentes rostros, porque mirados desde el patio, evidenciaban la miseria de su construcción "compuesta de tablas y latas viejas y sucias", según opinión de un inspector municipal, formando "todo un conjunto del más feo y asqueroso aspecto". Añadía que "una sola visita a esta propiedad deja la impresión de que es imposible que seres humanos puedan habitarlas" (12). Paredes hechas de "tabiquillo de adobes, tablas, planchas de zinc, latas agujereadas" (13). 


\section{URBA}

http://revistaurbanismo.uchile.cl

\section{2.- Tipologías}

En la práctica, el concepto conventillo se aplicaba a varios tipos de viviendas populares y colectivas. No siempre correspondía a la imagen tradicional, es decir, un edificio de uno, dos, o más pisos, con muchas piezas dispuestas en cuadro en cuyo centro y ocupando la primera planta estaba el patio o el pasillo común, el excusado y las artesas, como era el famoso "La Troya" y otros situados en el plan porteño. En el lenguaje corriente se llamaba de esta forma a toda casa de uso colectivo. Para los inspectores municipales conventillos eran indistintamente:

1. La casa grande y antigua, generalmente de material sólido, de uno o más pisos, arrendada por piezas a varias familias, y cuya unidad básica era el cuarto redondo, cada uno de los cuales tenía salida a la calle y no a un patio o pasillo interior o colectivo (ver Figs.1 y 2).

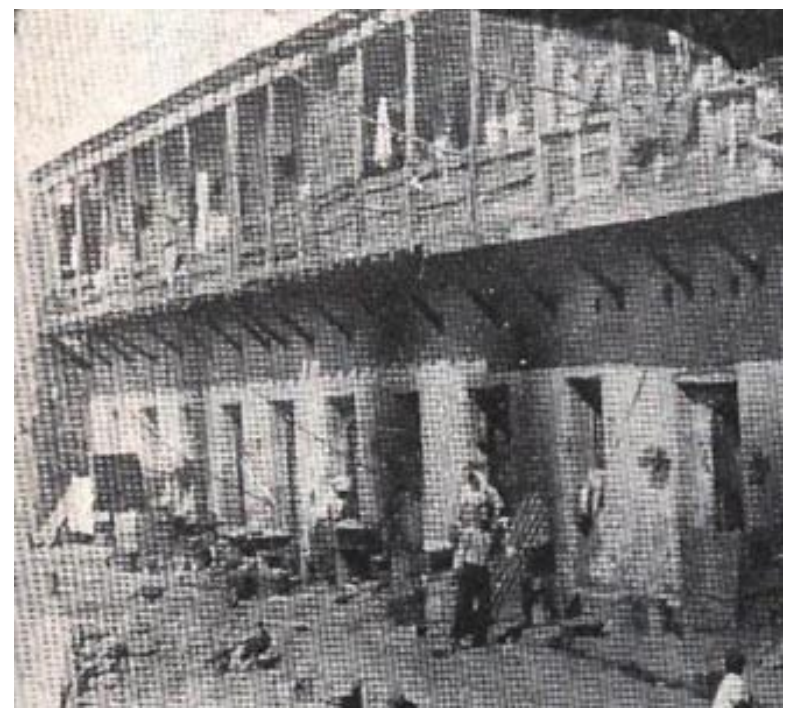

Fig.1. Conventillo $\mathrm{N}^{\circ} 1$, construcción de dos pisos compuesta de cuartos redondos sin patio y con salida a la calle.

Fte.: Revista Sucesos. N0559, Año XI. Valparaíso, 22 de mayo de 1913. 


\section{URBAANISMO}

http://revistaurbanismo.uchile.cl

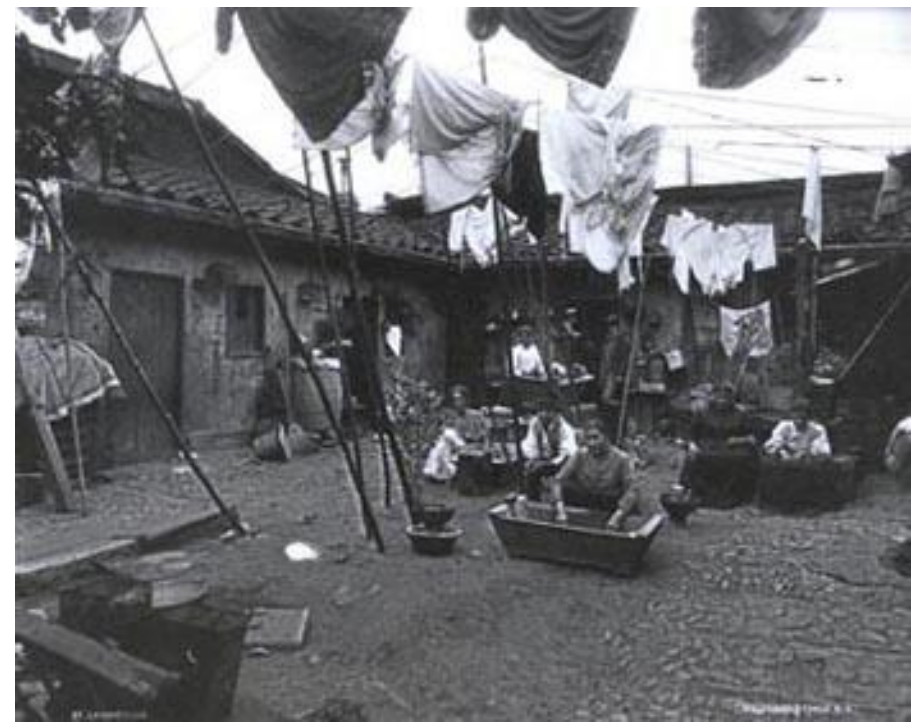

Fig. 2. Conventillo $\mathrm{N}^{\circ} 2$, construcción de un piso con patio central. Es el conventillo "tradicional". Conventillo del tipo $\mathbf{N}^{\circ} 1$, casa subdividida y adaptada.

Fte.: Olds Grant, Harry. Valparaíso 1900. Fotografías. Ed. J. Luis Granese Philipps. Santiago, U. Diego

Portales, Fundación Andes, Sudamericana de Vapores, 1998. Reproducción con fines culturales.

2. El conventillo propiamente tal, es decir, el edificio de uno o dos pisos con cuartos que tenían su puerta hacia un patio común y central. Era la forma básica, pero había variaciones, o esquemas degradados como eran los materialmente más pobres (ver Fig. 3). 


\section{REVISTA DE

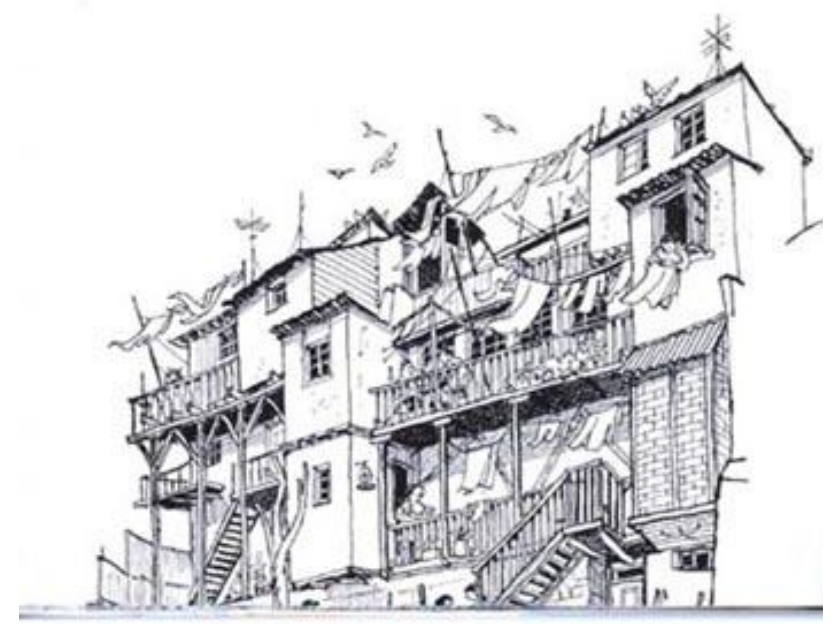

Fig. 3. Conventillo.

Fte: Renzo Pecchenino Raggi (Lukas). Apuntes Porteños. Valparaíso, 1995. Reproducción con fines estrictamente culturales.

3. Los ranchos, carpas o toldos multifamiliares instalados dentro de un sitio cercado por los propios arrendatarios o por el propietario, situados generalmente en cerros y quebradas. Estos eran los conventillos más elementales.

En la inspección hecha a las viviendas y establecimientos de la ciudad en el mes de diciembre de 1886, con motivo de fiscalización sanitaria sobre los tipos de "lugares" o excusados, ante la amenaza de la epidemia de cólera morbus, algunos de los inspectores, aquellos que reparaban más en los detalles, advirtieron otra modalidad de conventillos, que llamaron "cañón de piezas". Suponemos que correspondían a la mitad transversal de un conventillo de patio central, es decir, una sola hilera de cuartos dispuestas de manera perpendicular a la calle y que contaban con un pasillo o quizá en ocasiones un pequeño patio - entre las puertas de los cuartos y el muro o deslinde vecino. En general, las autoridades consideraban como "conventillo" a cualquiera de estos tipos de vivienda, tal como lo entendían los inspectores municipales y la opinión pública, porque, más que la forma y el tamaño de la construcción, era el colectivo y servicios comunes lo que justificaba llamarla conventillo, y "conventilleros" a sus moradores. Cualquiera fuese su tipología, el inquilino era arrendatario que pagaba un canon al propietario quien debía, en teoría, cumplir con las ordenanzas municipales sobre el estado material de la construcción, aguas, basura y excusado. 


\section{Importancia del estudio de los conventillos: su valor histórico}

El conventillo chileno como vivienda colectiva popular y urbana fue una realidad física o material que ocupó un lugar en la trama de la ciudad como un tipo peculiar de habitación surgida de la confluencia de factores sociales, económicos y culturales del período, siendo su característica la improvisación ante la demanda de un lugar dónde habitar y la escasa oferta de suelo dónde edificar. Fue un fenómeno urbano, propio de las grandes ciudades en el período que estudiamos (1880-1920), en el contexto de la Cuestión Social, cuando las ciudades como Santiago y Valparaíso actuaron como imanes que atrajeron migrantes desde el campo, de centros mineros y desde los centros urbanos menores tras oportunidades de trabajo cuyo resultado fue generalmente su marginalidad.

El conventillo es una realidad social porque consiste en un espacio de sociabilidad que se crea y reedita en cada uno de ellos. Como todo lugar en el que se cohabita, se generan relaciones sociales que se intensifican en el caso de los conventillos porque allí la concentración de población es mucha y el espacio es poco. La escasez material, la falta de espacio a causa de la intrincada topografía de Valparaíso y la precariedad de la vida impulsaron a que las relaciones sociales se hicieran más estrechas, complejas y diversas, y los lazos de solidaridad fueran más determinantes para, no sólo la convivencia, sino para la sobrevivencia.

El concepto que los contemporáneos tenían de "conventillo" en Valparaíso, creó otra dimensión, una representación mental, una percepción o imagen de habitación colectiva que perdura hasta hoy, y que corresponde al lugar estereotipado de morada y barrios diferenciados de la ciudad, asociado a los más extremos problemas de salubridad y de moralidad. En suma, una significación negativa que se intentó resolver con la "Ley de Habitaciones para Obreros" de 1906.

\section{4.- Conventillo y Cité}

No hay que confundir conventillo con cité. Los conventillos eran viviendas colectivas instaladas en casas unifamiliares adaptadas para tal fin, generalmente en mal estado o construcciones precarias levantadas o habilitadas para este objeto. Su característica principal era que cada familia disponía de una pieza que daba a un pasillo o a un patio común en el que ocasionalmente existía una fuente de agua y un servicio higiénico colectivo (14). El conventillo fue un espacio arquitectónico netamente urbano y popular, que permitió, en parte, racionalizar el crecimiento demográfico de la ciudad y enriquecer a sus dueños. Distinto es el caso del cité, que es definido como "un conjunto de viviendas, generalmente de edificación continua, que enfrentan un espacio común, privado, el que tiene relación con la vía pública a través de uno o varios accesos" (15). 
La principal diferencia entre conventillos y cités es que los segundos se diseñaron y edificaron con la intención de venderlos o arrendarlos como viviendas colectivas para obreros, y por lo tanto, su estructura, características arquitectónicas y su equipamiento son a propósito para el fin a que se le destina y la cantidad de personas que se espera que allí habiten. En otras palabras, el cité fue concebido como solución habitacional en reemplazo de los conventillos insalubres y para esos efectos fue construido, resultando ser higiénicos.

Se edificaron cités para grupos socio-económicos medios, pero mayoritariamente para los grupos populares, y sobre todo en Santiago, porque en Valparaíso no prosperó el impulso de la construcción, que debían asumir los particulares y no el Estado. Sin embargo, hubo cités porteños, y sus características físicas superiores a los conventillos fueron reconocidas por la población de la ciudad, que hizo distinción entre "conventillo insalubre" y "cité higiénico". Evidentemente, los habitantes de los cités estaban en un nivel superior en la escala socio-económica, porque sólo aquellos que poseían un trabajo asalariado y medianamente bien remunerado podían optar a alguna de las pocas "casas para obreros" dentro de los cités. Por lo mismo, y al ser propietarios, las condiciones de mantención de la vivienda colectiva eran muy superiores a los conventillos (16).

\section{Percepción o imaginario de los barrios pobres}

Había conventillos en todas las ciudades grandes en tiempos de la Cuestión Social, como Santiago, Antofagasta, Valparaíso y Concepción. En todas ellas el concepto y el contenido eran los mismos. La vida en la pobreza y en comunidad eran parecidas en todas partes, aunque la geografía modificara la construcción, porque paredes y techos variaban entre ciudades, la pileta de agua de Santiago y Antofagasta era reemplazada por la vertiente de la quebrada o la cañería en Valparaíso, y la acequia o canal en el centro del patio era propio de los conventillos de la capital, pero inexistente en el Puerto.

Sin embargo, todos merecían los mismos juicios: insalubres y miserables, así como idéntico reproche a la vida inmoral y a los excesos de sus habitantes. En el imaginario nacional, los conventillos eran pequeñas "Sodoma y Gomorra". En Valparaíso se los asociaba principalmente con los cerros, las quebradas, y lugares inaccesibles, a pesar de estar distribuidos por toda la ciudad, y se les describía construidos con cualquier tipo de material y generalmente identificados con la ropa tendida visible desde el plan, o por sus banderas blancas que testimoniaban cuarentena cuando las epidemias atacaban a la ciudad. En los conventillos de cerro se creía se originaban las pestes (17).

Era la percepción general -aunque, no la real-, porque el imaginario siempre situó la pobreza en lo alto, identificando indistintamente toda habitación ligera con la palabra conventillo. Era un modo de concebir a Valparaíso, porque las ciudades siempre se han percibido parceladas de ese modo, es decir, por barrios que sugieren imágenes negativas que permanecen a lo largo del tiempo con su significado original, como 
ocurre con el barrio Mapocho en Santiago, cargado mentalmente de una connotación de censura, tal como antes lo fue La Chimba. En Valparaíso, los sectores de cerros y quebradas permanecen en el imaginario como conceptos casi sinónimos de márgenes, suburbios, linderos o extramuros de la ciudad o "plan". Por eso se asocia a los conventillos con los cerros, aunque el mayor número de aquellos estaba en El Almendral. Los cerros eran visibles desde el plan, por lo que sus conventillos no pasaban desapercibidos, como sí ocurría más frecuentemente en Santiago. Sólo el porteño podía tener a la vista toda la ciudad como quien mira desde el escenario al anfiteatro, y en este caso, todo el paisaje urbano en altura, es decir, lo que identificaba con la pobreza y la marginalidad, o barrios de "la gente mala", como decía Joaquín Edwards Bello.

En el imaginario porteño había una ciudad-plan y una ciudad-cerro, cada una dotada de atributos distintos y hasta opuestos. La imagen generalizada era de ciudad alta, pobre y sucia, y ciudad baja, decente y limpia. Edwards Bello da su visión de Valparaíso en el año 1865, cuando el proceso inmigratorio era aún lento y la ciudad no estaba todavía completamente sobre saturada.

Dice que la "población de los cerros hace un contraste violento con la del plan o parte baja... Arriba está la plebe; abajo, las autoridades, los comerciantes, la alta sociedad. Generalmente son extranjeros los que empujan al cerro a los antiguos y auténticos habitantes de la caleta, que en la conquista se llamó Quintil. La ola europea, triunfante, va repeliendo hasta las quebradas pobres a los residuos o sobrevivientes de changos, mulatos y mestizos. El plan es la ley de Darwin. Hacia arriba va la ola medio derrotada comiendo pescado seco y cebolla" (18).

La misma visión de "separación residencial" confirmaba el diario La Unión en 1914, cuando "la parte plana de Valparaíso está ya totalmente ocupada, de modo que forzosamente la población tendrá que extenderse hacia los cerros" (19). La pobreza estaba arriba. Si el pobre quería permanecer en la ciudad debía encumbrarse a las alturas bajo la atenta mirada de las autoridades y la clase alta de la sociedad, que coincidían con Edwards Bello en ver en la pobreza la causa de todos los males sociales. Refiriéndose a la ciudad de los cerros, la prensa generalizaba cuando decía que los cerros eran de conventillos, queriendo significar pobreza y habitaciones ligeras amontonadas, es decir, una zona de tugurios (20). El Mercurio afirmaba en 1907 que "la población entera desde Portales a Playa Ancha está infestado de conventillos" (21), que el cerro Barón era "un solo e inmenso conventillo" y que todos tenían la característica común de las partes altas, o sea, "surcado de calles torcidas y desviadas en los infinitos vericuetos, sin dirección fija alguna" (22). Porque estas viviendas populares no se edificaban, sino que, para la opinión pública -y los pobres de la ciudad estaban excluidos de ella- se diseminaban, cual plaga que se propaga infestándolo todo, según los conceptos que se repiten en la prensa. Se forjó una representación mental, en que se tenía a la ciudad parcelada en "zonas decentes" y "zonas miserables", míseras de habitaciones y de gentes, o como dice Subercaseaux, barrios "acomodados y criollos" y barrios "populares" (23). 
Edwards Bello, al referirse a los cerros dice que arriba "hierve la gente maleante" y la califica de "carne de saqueo y revuelta", mientras el "plan", según él, pertenecía al "blanco", gente honrada, trabajadora y católica que, como la resaca que viene del mar, empujó al criollo expulsándolo del centro, "como expulsa la ola al cuerpo muerto". En 1906 decía que el cerro "es el socialismo vivo de Valparaíso con su larga bandera roja de tierra, de arcilla" (24). Edwards Bello observa dos dimensiones de una misma ciudad, ambas a la vista, con sus figuras contrapuestas. Por su parte, Benjamín Subercaseaux habla del "abajo" y el "arriba" como el leitmotiv de Valparaíso (25).

El porteño hacía una distinción entre el plan y el cerro, lo que quiere decir que "los grupos sociales han asignado valores simbólicos positivos o negativos con respecto al conjunto de la ciudad" (26), que en este caso eran dimensionamientos culturales o sociales basados más en prejuicios que en las características reales que presentaban los distintos sectores urbanos. Esto es lo que se ha llamado "marco mental", que le otorga al plan la condición de "blanco" y ciudad, y a los cerros, la condición de "oscuro" y margen. El cerro representaba un área homogénea y formada por diferentes accidentes topográficos con nombres propios, como por ejemplo, Placeres, Barón, Cordillera, que eran denominaciones que resultaban adjetivas, porque conformaban un "todo" cerro, o área "decadente" respecto de un "plan" o área "preferente". Sin embargo, decir simplemente cerro no era lo mismo que decir "cerro Alegre", porque a pesar de estar en altura éste era heterogéneo respecto de los demás cerros y homogéneo respecto del plan, y cuando Albert Davin se refiere a sus casas y a sus habitaciones, los asocia con el "sweet home" de los ingleses del Támesis o del Spree (27).

Los cerros criollos constituían un gran barrio compenetrado con el grupo humano que los habita, porque en el imaginario, el plan es "blanco" y el cerro es mestizo e indio. Esta afirmación es un estereotipo, y como tal, parece inmutable, regular y permanente (28), porque la imagen se estabiliza en la psiquis y se hace duradera. Imágenes y estereotipos se "fijan" en la mentalidad (29) que es colectiva y que es producto, como dice Paul Veyne, no sólo del hecho "de que varios individuos piensen lo mismo", sino que, "este pensamiento, en cada uno de ellos, está, de diversas formas, marcado por el hecho de que los demás lo piensen también" (30). El imaginario se retroalimenta con la complicidad. Al centrar nuestra atención en una "representación mental" ingresamos al campo de la "imagen colectiva" que nos da cuenta de cómo "los actores percibieron lo que hicieron; de qué manera entendieron su mundo, y cómo esa preocupación influyó sobre sus comportamientos, ya estimulándolos, ya inhibiéndolos" (31), dice Sergio Ortega.

La imagen que surge de la frase "cerros de conventillos" se repite a través del tiempo, porque "en la mayoría de los casos no vemos primero para luego definir, sino definimos primero y luego miramos" (31). Los habitantes de Valparaíso -y de cualquier otra ciudad constituida por barrios heterogéneos- eligieron aquello que ya estaba definido para ellos en el mundo urbano porteño, y tendieron a percibir lo que ya había sido estereotipado, es decir, cerro y plan. Por lo tanto, se adoptaron los esquemas mentales que se resisten al cambio y el concepto "cerro" fue inseparable de la pobreza, y ésta a la imagen de conventillo en cuanto a que éste concepto o imagen terminó por 
http://revistaurbanismo.uchile.cl

imponerse hasta identificar a todo barrio pobre, más allá de que fueran efectivamente sectores de conventillos.

El estereotipo se fabrica desde la perspectiva de la cultura en que el individuo está inmerso (33), es decir, es un tópico que valía tanto para el del plan o "gente de abajo", como para el del cerro o "gente de arriba". Y si el conventillo era asociado a la idea de epidemias, pobreza y delincuencia, todos los sectores pobres también lo eran. Por eso, aunque no sea real, el concepto conventillo es el que sintetiza las zonas "miserables" o "decadentes" de la ciudad, que el imaginario ubica en los cerros de Valparaíso.

Este imaginario se representaba también el plan, pero con sutiles diferencias entre el Puerto y el Almendral, porque a pesar de constituir éste último la mayor porción de la parte baja, era también suburbio o margen, sobre todo antes del terremoto de 1906. La distinta percepción se advierte en que se habla de "plan" y de Almendral como dos realidades urbanas distintas en una época en que el Almendral era caracterizado por la existencia de conventillos y por ser zona de anegamientos y barro, es decir, suciedad y desorden, aunque no era cerro, ni tenía el significado de las partes altas. Las palabras "plan", "Almendral", "cerros" evocan cada una de ellas una realidad particular, una jerarquía en el orden urbano, un tipo de habitante, una aceptación o rechazo, un prejuicio. La frase "sector de conventillos" alude a la ciudad del "otro", los porteños que Harry Olds Ilama "indios" y mestizos, y que Edwards Bello designa como criollos de los cerros que siempre están al acecho para "merendarse el plan", porque la ciudad del "otro" se supone hostil.

Edwards dice que en una ocasión vio a uno de estos hombres que bajó al plan a una asomada y cayó muerto en la refriega. Lo describe así:

"...era un muchachón de esos que llamamos con justicia rotos, porque van hechos una compasión mostrando las carnes por cualquier parte del cuerpo; había bajado al río revuelto desde su cerro; no tenía nada que perder... Por entre los andrajos divisábase su carne oscura con verdaderas costras de mugre seca, mugre antigua, el sudor amasado con caspa desde que nació; su boca estaba abierta mostrando todo el cinismo interior; era la última cara que guardaba el roto para el banquillo... Desde su cabeza colgaba una cosa viscosa y blanca con vetas rojizas; era el cerebro, era lo que había pensado, la parte humana que había hecho sonreír a este desgraciado... Quizá si hasta amó alguna vez..." (34).

El literato no dice si el infortunado vivía en un conventillo, rancho o tugurio, pero eso no importa, porque el imaginario situaba allí a la "gente mala", como él mismo dice.

\section{Imagen popular del conventillo}

El concepto de conventillo deriva del convento religioso, en cuanto conventus significa congregación, reunión. Por abandono, los conventos terminaban siendo el albergue de los pobres, que los ocupaban colectivamente a manera de vivienda social (35). El concepto conventillo ocupa, por lo tanto, un lugar en el imaginario porteño como la 
representación mental de un tipo de vivienda colectiva que existió en el pasado, identificada con los grupos sociales más pobres, con la estrechez del espacio y el hacinamiento de personas. Es la descripción física del "conventillo" que, obviamente, no quiere decir "convento pequeño", como lo dice el Diccionario, ni podría ser identificado con la vida religiosa. Por otra parte, el concepto representa también un "modo de vida", porque al pronunciar la palabra "conventillo" la asociamos mentalmente a las habladurías sobre terceros y que llamamos "conventilleo" en lenguaje popular, cuyo origen está en que la vida privada quedaba expuesta y a merced del comentario del resto de los co-habitadores (36). En cierto modo tiene su paralelo en la frase "pueblo chico, infierno grande", precisamente porque todos se conocen. Entonces, además del ámbito físico del conventillo, se alude también al tipo de vida o "vida de conventillo".

Desde otro punto de vista, el concepto está lleno de contenido negativo en lo social y moral: insalubridad, vicios, delincuencia y perversión. Hoy, el concepto conventillo se ha extendido también al cité, absorbiéndola como sinónimo, aunque originalmente no eran lo mismo, sino que el segundo era una versión mejorada y más moderna que el primero. En la actualidad, lo que la gente llama conventillos no son sino cités modernos e higiénicos. Pero la imagen ha sobrevivido al tiempo, y la opinión generalizada es que en la ciudad "aún quedan conventillos", dicho con cierta morbosidad, porque se sabe que eso significa suciedad, pobreza, violencia promiscuidad, aunque en ocasiones se reconoce también que el concepto encierra relaciones de solidaridad entre los vecinos. A nadie le resulta indiferente el concepto, porque genera cierta curiosidad -a veces, como decíamos, morbosa-, y el imaginario une la tipología de vivienda a sus características culturales y sociales. Por eso, la palabra conventillo dibuja mentalmente un cuadro que representa una vivienda, olores, colores, ropa tendida, mujeres ocupadas en algo, numerosos niños jugueteando, miseria, violencia en el lenguaje, y antro o tugurio peligroso para el foráneo.

El mismo "carácter" de conventillo, tan definitorio como sus rasgos físicos, constituye un estereotipo donde la sociedad resumió todo lo negativo que había en ella, comparándolo a veces con el infierno en la tierra. Es decir, era lo opuesto a la noción de casa privada. Manuel Rojas dice:

"Muy poca gente sabe la diferencia que existe entre un individuo criado en un hogar donde hay limpieza, un poco de orden y ciertos principios morales...y otro que, o ha tenido lo que se llama hogar, una casa aparte o unas piezas en ellas y no un cuarto de conventillo en que se hacinan el padre con la madre, los hijos y el yerno, algún tío o un allegado, sin luz, sin aire, sin limpieza, sin orden, sin instrucción, sin principios de ninguna especie, morales o de cualquiera otra índole; el padre llega casi todos los días borracho, grita, escandaliza, pega a la mujer, a los niños y a veces al tío, al yerno o al allegado" (37).

No obstante, los conventillos tenían cierta áurea. Estaban llenos de vida, no eran anónimos y eran reconocidos por sus nombres. Se diferenciaban de otros edificios porque tenían un olor particular que era la suma de todos los olores, de ellos "surgían tufaradas de humedad, ráfagas de aire pegajoso, tibio, como muchas respiraciones 
http://revistaurbanismo.uchile.cl

exhaladas a un mismo tiempo..." (38). Podía reunir todos los defectos, pero para el morador debió ser una conquista: un cuarto, un techo y una colectividad vecinal por compañía que con mucho superaba el primitivo y débil rancho colgado de la ladera.

Desprendemos de la documentación, que el poblador lo sintió como propio, a pesar de los juicios negativos, y a pesar también de sus propias miserias. Se connaturalizó con ellos y se hizo impermeable y hasta creyó que para él no había otro lugar mejor. Esto último se prueba por la resistencia a abandonar el cuarto aun cuando las aguas o el terremoto de 1906 haya causado estragos en el conventillo. Mejor se estaba en el hogar que en las carpas de la Plaza.

Y aunque no era su propiedad, era su morada, y tal como el vecino solvente, orgulloso de su casa cómoda y señorial le da el nombre de "villa", el habitante de conventillo reconocía en el suyo una personalidad forjada en su fama de "ciudadela", incluso llamado con nombre propio, como un "alias", tal como los apodos de sus inquilinos.

No era necesario el número de la casa o el nombre de la calle para identificarlo, bastaba decir "El Cabo de Hornos", famoso por su hacinamiento y por los delincuentes que allí se refugiaban, igual que "La Troya", el "Billa", o "La Unión". Otros tenían nombres curiosos como "El 14 Puertas", "La Parafina", "La Compañía", o la "Recova Vieja", este último en el cerro Cordillera, o nombres de país lejano como el "Liguria", tal vez bautizado por su propietario Oreste Cingarotti y situado en calle Chacabuco(39). Había nombres como El "Americano", que estaba en calle del Hospital N0267(40) del cerro Alegre, el "Cité Faveró" en el plan, mientras que en el cerro Barón se encontraba el "Gran Conventillo Bentancourt"(41), o nombres de árboles frutales, como "El Peral" en la calle de Santo Domingo(42), o "La Higuera"(43), en el cerro de la Cruz.

Personas que durante su infancia vivieron en conventillos de Valparaíso, en el plan y en los cerros -posiblemente conventillos más habitables que los casos incluidos en este estudio-, a pesar de describir pormenorizadamente la estrechez, la existencia de un único excusado para numerosa población y de una llave del agua con su escaso líquido, al recordar aquellos años destacan los aspectos positivos, sobre todo el sentido comunitario y la solidaridad. Se valora que nadie estaba completamente solo, que nunca se abandonaba a un enfermo ni a un anciano, que los cumpleaños, matrimonios y bautizos se celebraban en el patio del conventillo, que el 18 de septiembre y el Año Nuevo eran fiestas de la vecindad antes que familiar o de la ciudad, y a nadie le faltaba algo que comer, porque el egoísmo no era posible en esa situación. Se recuerda con cierta nostalgia la vida en colectivo, donde cada morador pasaba a ser "un personaje" dentro de la cotidianeidad, donde todos conocían el horario y las costumbres de cada uno, y los niños ponían sobrenombres a los vecinos, cuando se hablaba de "mi" conventillo, con un sentido de pertenencia, de hogar común y de familia grande, tal como suelen recordarse las casas de antaño. 


\section{Percepción periodística y oficial del conventillo}

Menos personal y más peyorativa era la imagen que los observadores externos tenían de los conventillos. No había diferencia entre autoridades nacionales y municipales, la prensa, los vecinos pudientes, o las organizaciones de higiene y salud, al pronunciar o escribir "conventillo", palabra acompañada siempre del adjetivo calificativo insalubre.

"Cuevas", los llamaba El Mercurio, (Valparaíso, 24 de enero de 1887).

"Inmundo Rancho", decía La Defensa Obrera, (Valparaíso, 20 de diciembre de 1913).

"Verdaderas cuevas de repelente aspecto", se lee en La Patria. (Valparaíso, 25 de agosto de 1886).

"Tumbas del proletariado". (La Unión. Valparaíso, 20 de agosto de 1893).

"Pocilgas calculadas para matar a los que las habitan". (La Unión. Valparaíso, 20 de agosto de 1893).

"Mortíferas cavernas Ilamadas conventillos". (La Estrella del Progreso. Valparaíso, 10 de octubre de 1876).

"Tugurios infectos y repugnantes". (La Unión. Valparaíso, 25 de marzo de 1911).

"Pocilga inmunda llamada conventillo". (La Unión. Valparaíso, 16 de enero de 1912).

"Son un chiquero, inferior en calidad a los destinados a mantener rebaños y ganados" (El Mercurio. Valparaíso, 8 de enero de 1887).

"Sepulturas". (El Mercurio. Valparaíso, 24 de enero de 1887).

"Ratoneras". (El Chileno. Valparaíso, 22 de abril de 1914).

"El idioma castellano, tan rico en palabras, no las tiene suficientemente propias para describir con mediana decencia semejante pocilga". (El Mercurio. Valparaíso, 18 de marzo de 1909).

La prensa era implacable y su visión negativa queda reflejada en los calificativos usados que ilustran muy bien la miseria de la construcción, los cuartos y el estado lamentable en que vivían sus habitantes. Los historiadores han recogido idéntica imagen citando impresiones de la época: 
http://revistaurbanismo.uchile.cl

"Hervideros de mugre, antros de corrupción, escuelas de crímenes, mataderos humanos", (Barahona, A. Habitaciones para obreros. En: Ugarte Yávar, Juan de D. Valparaíso 1536-1910. Recopilación histórica, comercial y social. Op. Cit.).

"Focos de infección, de muerte, de vicio, almacenes de depósito para proveer de víctimas a las cárceles y a los hospitales", (Editorial de El Ferrocarril. 14 de agosto de 1872. En: Grez Toso, Sergio. La "Cuestión Social" en Chile. Ideas y debates precursores (1804-1902). Op. Cit.).

"Indecentes pocilgas populares", (Revista de la Habitación, Año I, No9, julio de 1921).

\section{En suma}

Para sus contemporáneos el conventillo no era sólo una vivienda mil veces reproducida, sino que fue además una realidad en el imaginario colectivo propiamente nacional, tal como lo son los conceptos de "palacio" o "castillo". Porque, la ciudad está hecha de memorias que se encuentran en cada esquina y recoveco, incluyendo los barrios centrales y periféricos, comerciales y residenciales.

Las laderas de los cerros y los fondos de las quebradas también tienen mucho que decir sobre el pintoresquismo de Valparaíso, porque forman parte del imaginario porteño, han hecho y están haciendo la ciudad.

Viviendas urbanas, colectivas, pobres y precarias del pasado, pero que aún tienen presencia en la ciudad, como los ranchos encaramados en las laderas de los cerros ahora subdivididos e higienizados, transformados en cités-, merecen la atención de arquitectos, historiadores, urbanistas, sociólogos, psicólogos sociales y geógrafos urbanos.

\section{Referencias}

(1) HAVEL, J.E., Habitat y Vivienda, Buenos Aires, Eudeba, 1961 (1a edición de 1957), pág. 11.

(2) Moffatt, Alfredo, "Psicología de la vivienda popular", en: Revista de Arquitectura, No 198, Buenos Aires, Sociedad Central de Arquitectos.

(3) Para el caso de Santiago, ver a: DE RAMÓN, Armando; GROSS, Patricio (Compiladores), "Santiago de Chile: Características histórico-ambientales, 1891-1924", Londres, Monografías de la Nueva Historia, 1985; ROMERO, Luis Alberto, "Condiciones de vida de los sectores populares en Santiago de Chile, 1840-1895 (Vivienda y Salud)", en: Nueva Historia, No9, Vol. 3, Londres, 1984.

(4) Ver el siguiente artículo sobre Santiago: SALAZAR, Gabriel, "Empresariado popular e industrialización: la guerrilla de los mercaderes (Chile, 1830-1885)", en: Proposiciones, N020, Santiago, 1991.

(5) Revista de Higiene, Tomo VII, Santiago, 1901.

(6) El Mercurio de Valparaíso, 3 de diciembre de 1995.

(7) Viaje de la fragata austríaca "Novara" alrededor del mundo, en 1859, en: Anales de la Universidad de Chile, Tomo XXIII, No 6, 1983, en: CALDERÓN, Alfonso, Memorial de Valparaíso, Valparaíso, Ediciones Universitarias de Valparaíso, Universidad Católica de Valparaíso, 1986, pág. 234.

(8) EDWARDS BELLO, Joaquín, Memorias de Valparaíso, Selección de Alfonso Calderón, Santiago, Editorial Zig-Zag, 1969, pág. 73. 
http://revistaurbanismo.uchile.cl

(9) El Mercurio de Valparaíso, 5 de abril de 1907. Artículo titulado "Cómo vive nuestro pueblo".

(10) WIENER, Charles, Chili et chiliens. París, 1888, pág. 26. Citado en DE RAMÓN, Armando; GROSS, Patricio (compiladores), Op. Cit., capítulo "La vivienda", de Armando de Ramón. Pág. 83.

(11) La misma comparación con las "piezas alineadas como los camarotes de los barcos la encontramos en SUBERCASEAUX, Benjamín, Chile o una loca geografía. Santiago, Editorial Universitaria, 1995, pág. 128, $1^{\text {a }}$ Edición de 1940.

(12) Archivo Municipal de Valparaíso (AMV). Vol. 181, No 407, 2 de agosto de 1910. Informe de un inspector de la Policía Urbana sobre el conventillo de calle Cajilla No 197, de propiedad de Alejandro Vera.

(13) AMV. Vol. 90, 3 de julio de 1903. Oficina de Inspección de Sanidad.

(14) ORTEGA S., Oscar, "El Cité en el origen de la vivienda chilena", en: Ciudad y Arquitectura (CA), No 41, Santiago, septiembre de 1985, pág. 19.

(15) VIdem, pág. 18.

(16) A veces un conventillo podía transformarse en un cité, cuando el propietario reformaba la antigua construcción e instalaba galpones para lavar, W.C. y servicio de agua potable abundante. El valor del arriendo subía y accedían a él sólo los obreros asalariados de mejor pasar.

(17) Sobre los males de la pobreza ver a: LORENZO, Santiago, "Vida y problemas urbanos", en: LORENZO, Santiago; HARRIS, Gilberto; VÁSQUEZ, Nelson, Vida, costumbres y espíritu empresarial de los porteños. Valparaíso en el siglo XIX. Valparaíso, Instituto de Historia, Universidad Católica de Valparaíso, Serie Monografías Históricas No11, Ediciones Universitarias de Valparaíso, 2000; URBINA BURGOS, Rodolfo, Valparaíso, Auge y Ocaso del Viejo "Pancho". 1830-1930, Valparaíso, Editorial Puntángeles, 1999; FIGARI, Ma Teresa. "Insalubridad y pobreza en Valparaíso. 1850 a 1930", en: Intus Legere, No 3, Santiago, 2000; FLORES, Sergio, "Factores que determinan la salud pública en Valparaíso (1854-1904)", en: Revista de Ciencias Sociales, N031, Universidad de Valparaíso, Valparaíso, 1987.

(18) EDWARDS BELLO, Joaquín, El bombardeo de Valparaíso y su época, en: Calderón, Alfonso, Memorial de Valparaíso, Op. Cit., pág. 264.

(19) La Unión de Valparaíso, 14 de enero de 1912.

(20) Tugurio se define como "vivienda infrahumana, insuficiente en cuanto espacio e iluminación natural, aireación, asoleamiento; generalmente construida de materiales deleznables y/o desecho, con ausencia de tecnología, y habitada en condiciones de hacinamiento". BODINI CRUZ-CARRERA, Hugo, Geografía de Chile, Tomo X, Geografía Urbana, Santiago, Instituto Geográfico Militar, 1985, pág. 220.

(21) El Mercurio de Valparaíso, 7 de abril de 1907.

(22) Idem.

(23) SUBERCASEAUX, Benjamín, Op. Cit., pág. 118.

(24) EDWARDS BELLO, Joaquín, "Valparaíso ayer y hoy" (de "Crónicas. Valparaíso-Madrid, 1924"), en: Calderón, Alfonso. Memorial de Valparaíso. Op. Cit., pág. 372.

(25) SUBERCASEAUX, Benjamín, Op. Cit., pág. 125

(26) BODINI CRUZ-CARRERA, Hugo, Op. Cit., pág. 210.

(27) DAVIN, Albert, Chile y Perú en tiempos de la Guerra del Pacífico, traducción y notas de Fernando Casanueva Valencia, presentación de Leopoldo Castedo, Santiago, Editorial Planeta, 1992, pág. 129.

(28) Ver a DE CASTRO, Constancio, La geografía en la vida cotidiana: de los mapas cognitivos al prejuicio regional, Barcelona, Ediciones del Serbal, 1997, pág. 152.

(29) De entre las muchas definiciones de Mentalidad, nos quedamos con la formulada por Nilda Guglielmi, porque la perfila como constituida "por las ideas, opiniones, creencias, que integran el patrimonio de todos, ideas que han pedido su racionalidad, operan, actúan. Son el conjunto de 'ideas corrientes', de ideas operativas, que funcionan efectivamente en una sociedad, que no han sido nunca expuestas se manera expresa y sistemática". GUGLIELMI, Nilda, Marginalidad en la Edad Media, Buenos Aires, Editorial Biblos, 1998 (1a Edición Eudeba, 1996), pág. 13.

(30) VEYNE, Paul, "La historia conceptualizante", en: LE GOFF, Jacques; NORA, Pierre, Hacer la Historia, Barcelona, Editorial Laia, 1985 (1a Edición, París, 1974), pág. 91.

(31) ORTEGA NORIEGA, Sergio, "Introducción a la Historia de las Mentalidades", en: VV. AA, El historiador frente a la Historia. Corrientes historiográficas actuales, México, Universidad Autónoma de México, 1992, pág. 89.

(32) DE CASTRO, Constancio. Op. Cit., pág. 153, citando a LIPPMAN, W. Public Opinion, Harcourt Brace Jovanovitch, 1922.

(33) Idem, pág. 153. 


\section{REVSTADE \\ URBANISMO}

http://revistaurbanismo.uchile.cl

EDWARDS BELLO, Joaquín, "Valparaíso ayer y hoy" (de "Cró
Calderón, Alfonso, Memorial de Valparaíso, Op. Cit., pág. 377.

octubre del 2001. C12.

(36) Baldomero Lillo, en uno de sus "Relatos Populares" editados por El Mercurio de Santiago en las primeras décadas del siglo XX, publica uno llamado "Las Niñas", que tiene lugar en un conventillo. Expone cómo las arrendatarias mujeres están ansiosas por saber la edad exacta y el pasado de las dos señoras ya ancianas recién llegadas al conventillo. El literato describe así el ambiente: "Por las tardes, terminados sus quehaceres, las locatarias del conventillo salían a las puertas de sus viviendas y entablaban entre sí diálogos para comentar las noticias del día. Después de discutir el último chisme o escándalo que circulaba en el pueblo, la conversación recaía invariablemente en las encajeras [las "niñas"]. Jamás asunto alguno les había interesado tanto, y la extraña conducta de las hermanas, cuyo móvil trataban inútilmente de descubrir, les daba asidero para las más fantásticas suposiciones". Agrega el narrador que el aislamiento de las hermanas era incomprensible para las mujeres del conventillo porque "venía a romper esa tradición de igualdad que la vida en común impone del conventillo impone a todos sus ocupantes". LILLO, Baldomero, "Las Niñas", en: Obras Completas, Santiago, Editorial Nascimiento, 1968, pág. 336.

(37) ROJAS, Manuel, Hijo de Ladrón, Santiago, Zig-Zag, Colección Viento Joven, 1998, pág. 140.

(38) ROJAS, Manuel, Lanchas en la bahía, Santiago, Editorial Zig-Zag, 1960, pág. 32.

(39) La Unión de Valparaíso, 14 de enero de 1911.

(40) AMV. Vol. 89. Consejo Departamental de Higiene. № 32, 30 de diciembre de 1898.

(41) La Unión decía que vivían allí al menos 500 adultos y 300 niños. La Unión de Valparaíso, 7 de febrero de 1925.

(42) AMV. Vol. 109. Inspección de Servicios Municipales. No 317, 14 de abril de 1905.

(43) Archivo Judicial de Valparaíso (AJV). 2do. Juzgado del Crimen, Legajo No 470, 12 de agosto de 1900. 